\title{
In Search of Gender Justice: An Analysis of the Arguments of Two Ghanaian Feminist Groups
}

\author{
Mustapha Abdul-Hamid, Ph.D. \\ Department of Religion and Human Values \\ University of Cape Coast \\ Cape Coast, Ghana \\ Nana Aba K. Forson \\ Centre for International Studies \\ University of Ohio \\ Athens, USA
}

\begin{abstract}
The world is generally perceived as favorable to men and unfavorable to women. Since the Beijing Declaration of 1995, women around the world continue to advocate for the dismantling of the patriarchal structures that inhibit their development.The Network for Women's Rights (NETRIGHT) and ABANTU for Development, have been vocal in the fight forwomen's rights in Ghana since the post-Beijing era. In 2017, two groups - Pepper Dem Ministries and Sugar Dem Ministries emerged, taking advantage of social media to establish a national presence. Their activities raised the discourse on women's rights and generated huge national debate on gender justice. This paper examines the arguments of these two groups on proposed strategies to achieve gender justice. The study argues that though the activities of these groups have helped to raise the awareness of pervasive gender injustice in the Ghanaian society, the proposed strategies adopted by these two groups will not achieve the desired result of ensuring gender justice. Instead, the paper proposes a middle ground strategy, that is neither confrontational nor docile.
\end{abstract}

Key words: Gender, Justice, Women, Pepper Dem, Sugar Dem

\section{Introduction}

This paper examines the different approaches adopted by two feminist groups to address the problem of gender injustice in the Ghanaian society. Gender injustice refers to the imbalance that exists between men and women as far as access to social, political and economic goods is concerned. These groups are the Pepper Dem Ministries (PDM) and the Sugar Dem Ministries (SDM). PDM and SDM are feminist groups in Ghana, made up of mainly educated, young and upwardly mobile women in white-collar jobs.

The 2010 Population and Housing Census registered 50.4\% of the Ghanaian population as women, while men constitute $49.6 \%$. Yet, $67.3 \%$ of the male population are literate, while only 32.7 of women areeducated. Currently, $43 \%$ of males are enrolled in school, while only $28.3 \%$ females are enrolled. In Ghana's parliament of 275 members, only 36 are women. In almost all the development indices, the scales are weighed heavily against women. It would therefore appear that there is gender injustice in Ghanaian society. This gender imbalance is favorable to men and unfavorable to women. Even though many educated Ghanaian women seek ways to address this gender imbalance, their approaches differ considerably.

PDM, the first to be formed, presented itself as a radical feminist group, advocating for a 'flipping' of the script. In other words, they advocated for all the norms that disadvantage women to be overturned, such that men now occupied the side of the binary where women experience marginalization (whether domestic or public). PDM argues that by flipping the script, men will appreciate the difficulty that women go through in their lives. PDM proposes for example, that just as society allows men to marry more than one wife, it is fair that women are given the privilege to also marry more than one man. Similarly, men shouldcook for their wives instead of allocatingwives to domestic duties. As such PDM's modus operandi is calling for the "flipping" of all the cultural and social privileges accorded men.

The PDM group started as an online campaign group but transitioned into a regular women's advocacy group. It attracted both praise and condemnation in equal measure. Condemnation came from men and women alike. However, most of the criticism against the PDM came from the SDM which was formed in response and as a counteractive move to the activities of the PDM. SDM's criticism of the PDMactivities and arguments can be analyzed in three strands by way conceptualization. First, they contended thatthe search for gender justice by women should not be confrontational. Indeed, their name, Sugar Dem, tells the philosophy that underlines their advocacy for gender justice. To them, rather than "peppering" men, women should "sugar" men. 
They contend that men control the power structures of the world, and confronting them will set men and women on a collision course, which in their view, will further be disadvantageous to women. Secondly, SDM contends that the gender philosophies espoused by the PDM group are western philosophies that have no resonance or relevance to the African discourse. Lastly, they argue that, men and women cannot be "equal" in the literal sense of equality. To SDM, the fact that men and women are biologically distinct, shows that they were not meant to be equal.

This paper examines in detail, the arguments of these two feminist groups in the light of modern theories of gender. This paper holds thatboth the positions of PDM and SDM have some merit. However, the paper concludes that the arguments of PDM and SDM needs to be synthesized to achieve gender justice in Ghana.There is a lot of literature on gender and the frames of reference as espoused by these two groups are not new as far as the gender question is concerned. We now turn our attention to some existing literature that helps set our discussion in perspective.

\section{Review of Related Literature}

Brahmitash (2008) for example examines the gender question in relation to Iranian society and how western feminist theory pretends to have the answer for curing gender injustice in Iranian society. But Brahmitash (2008) argues that the quest for gender justice cannot be achieved on the basis of a universal cultural formulation. In other words, how gender is negotiated is also a product of culture. Sometimes, what is considered oppressive in one cultural context may not connote oppression in another cultural context. Using the veil as an example, she argues that the stigmatization of the veil in western gender discourses is misplaced. There is the misconception that the veil is an imposition by domineering Arab men and that the west would have to work to liberate Arab women from the oppression of the veil. She rejects this imperialistic savior thinking. Rather, she argues that there are many women in Iran and for that matter women in the Arab and Muslim societies across the globe who wear the hijab as a matter of choice and identity.

We agree with Brahmitash's argument and add that there is a certain 'orientalist' mentality that pervades western literature on gender. By 'orientalist,' we borrow Said's (1978) terminology that posits that western writing on other cultures, especially on cultures of the East, is often laced with "racism, cultural stereotypes, political imperialism and dehumanizing ideology..." (p.27).

It is for this reason that Amenga-Etego (2011) argues that "the current state of discourse on gender in Africa is beset with contradictions and ambiguities" (p.154). She therefore avers that"contextual studies" is a more realistic means of substantiation. By "contextual studies," she means that the peculiarities of every culture ought to be taken into consideration in any discourse on gender. This point is buttressed by Brahmitash (2008) when she argues that the "one-size-fits-all" type of solution to the gender question is a function of binary thinking. This binary thinking assumes that western culture is liberating while other cultures are oppressive. And this argument is germane to the grain of this paper, in the sense that the SDM makes this point precisely, when they state that the PDM ought to factor Ghanaian cultural sensitivities and arrangements into their arguments on gender justice.

Grewal \& Kaplan (2006), argue that in a globalized world, it is difficult to argue that one set of culture should not influence another culture. To them, globalization means a world in which cultures both interact and influence one another. The argument by Grewal \& Kaplan (2006) is relevant for our work in the sense that, we conclude that Ghanaian women need to carve a uniquely Ghanaian strategy for advocating for gender justice in the Ghanaian society. Thus, for SDM to argue that PDM cannot import western gender frames as a model for women's liberation in Ghana, is without basis. Indeed, we live in an interdependent world, and to suggest that we cannot cross-fertilize ideas for the purpose of improving the lives of women is, in our view an over simplification of the issues.

Pratt \& Rosner (2012)show how the intimate "is infused with worldliness" (p.3). For them, intimacy does not reside solely in the private sphere. "Intimacy takes on specific political, social and cultural meanings..." (p.3). PDM argues that, the family system in Ghana does not foster intimacy. For PDM, the family system in Ghana is a theatre of oppression for women, where women are reduced basically to being domestic slaves for men. They argue that when the Ghanaian society expects women to cook and wash for men, then society negates the principle of intimacy within the home. This point by PDMhas some validity. Pratt \& Rosner (2012), argue that, intimacy connotes "love, sex, informality and personal connection" (p.4). A domestic setting where there are strict gender roles evokes formality, rather than informality and in that sense the "personal connection" that is required to generate love, is missing.

Alhayek (2014), argues that in most cases, online campaigns that aim to fight for the rights of marginalized groups, are in fact, divorced from the everyday reality of these groups. She argues that first of all, what these online activist groups perceive as being the problem of the marginalized groups for whom they purport to speak, may in essence, not be the real problem that these marginalized groups face. Secondly, these marginalized groups "do not have the economic and educational privileges to access the online spaces to speak for themselves" (p.3). In doing so, she also invokes Ong's (1999) term, "self-orientalization." Alhayek (2014) refers to self-orientalization to mean that local activists, having imbibed Western orientalist thinking, assume a certain Saviour-thinking, which presumes to know the problems of their marginalized compatriots. 
Alhayek's (2014) article is of relevance to our work in the sense that, PDM started as an online campaign that purported to speak for Ghanaian women. But were the issues they were articulating the major concerns of Ghanaian women? In none of their online posts did they articulate the issue of poverty or lack of access to credit and the predominance of illiteracy among Ghanaian women. These are the issues that are germane to women's development. Of course, because the majority of Ghanaian women are uneducated, they do not have access to online resources to fight for themselves. PDM was therefore basically engaged in "self-orientalization" in the sense that because of their education and training, they purport to know the problems confronting women.Likewise, they presume to 'speak' for women based on what we consider as purely theoretical, academic and philosophical postulations that do not reflect the real needs of women outside Facebook or Twitter. Below are three of the posts that they shared on their Facebook wall between June and August 2018 under a broad theme they call \#unlearning toxic narratives.

Maybe if we start replacing 'I want to marry you' with 'should we get married, ' we will start thinking of marriage as a partnership $\left(27^{\text {th }}\right.$ June 2018). Women belong in the kitchen. Men belong in the kitchen. Everyone belongs in the kitchen. The kitchen has food $\left(9^{\text {th }}\right.$ August, 2018). I don't know how you expect me to cook for you because it is my "duty" as a woman, but when I ask you to send me dollars, I am a hoe/gold digger/ If you want me to patriarch for you, you would better be willing to drop some patriarchy money. Am I a joke to you? (22 ${ }^{\text {nd }}$ August, 2018).

In a country where $50 \%$ of the population are women with only 28.3 percent of them in school, $32.7 \%$ educated and 36 women as members of the legislature out of 275 members, it is expected that these are the matters that should engage the attention of any women's advocacy group. Issues of who should propose marriage to who and who should cook for who will not contribute to a qualitative transformation of the lives of women.

PDM asserts that African cultures are suffocating to women. They therefore, advocate for a reformation of aspects of African customs and traditions that subjugate women and reduce their dignity and esteem. The PDM argues that the Ghanaian assimilation of Christianity and Islam with African traditions are a toxic mix, that robs women of their freedoms and makes them subservient to men. It is to this that Abdul-Hamid(2017) alludes, when he discusses how the Dagomba people, through the assimilation of Islam with Dagomba tradition, have created an environment that is unfavorable to women.

The above literature review is meant to set a context for the discussion that will follow. The list is not exhaustive and in the course of interrogating the issues raised by both the PDM and SDM, we shall be interacting with other literature that illuminate the arguments of this group. We shall now turn to the theoretical underpinnings of their arguments, since that will help us situate the basis of their debates.

\section{Theoretical framework}

To further illuminate the arguments that these two Ghanaian feminist groups make, we examine three gender-based theories as they apply to the central issues of discussion in this paper, as espoused by the PDM and SDM.

Gender theories are theories that seek to explain the relationship between men and women in society, how these relationships are constructed and internalized by both sexes and how they determine the behavior of men and women in society. For this paper, we shall examine three of such theories as they relate to the arguments made. These are Existentialism, Radical Feminism and African Feminism.

Existentialism is the phenomenon that postulates thatwe live in a world of binary opposites. It claims thatfrom the beginning, man has named himself, the 'self' and woman, the 'other.' This binary allows man to subjugate woman to the point where woman, like man, has "internalized the alien point of view that man is the essential, woman the inessential" (Hall, 1997, p.229). Indeed, as has been shown already, the SDM, mirrors this internalization. They have internalized the male narrative thatman is essential while woman is inessential. They even acquiesce to pamper, feed men, cook for men with the hope that men will sugar them in return. They demonstrated this publicly with cooking for men on Valentine's Day in 2018.

Existentialism is relevant to this paper in the sense that, SDM wants the categorization of men as essential and women as inessential, to be maintained. They accept the bifurcation of roles that society assigns to men and women by reason of their biological make-up.

In an article dated March $9^{\text {th }}, 2018$ and published onmyjoyonline, Isaac Kyei Andoh, shows absolute disdain for the position of the SDM when he states that "in my estimation, Sugar Dem is bereft of common sense and an affront to the call for respect for women." He avers that, the argument by SDM, that women should pamper men in order to be treated right "is like blaming the oppressed for her woes and asking her to do more for the oppressor. "Asking the one suffering to do more for the one enjoying means that I cannot align with such a group" he stated. SDM are naturalists in that sense. They believe that our biology springs from our nature. They surmise that our nature determines our roles in the society. Therefore, they do not see reason with the PDM that we should fight to change the dominator-dominated model that patriarchy imposes with existentialist thinking. While the SDM are considered existentialists, the PDM are regarded as radical feminists. Radical feminism seeks to challenge gender norms in a revolutionary way, that completely flips the script. 
In a series of Facebook posts by members of the group, they continually raised imaginary scenarios and implored people to consider flipping the script and see if men were going to be prepared to accept their new position. Radical feminism takes the position that men should not be "sugared." Instead, they should be "peppered". The SDM countered PDM narratives by arguing that African customs advocate for respect to be shown to men, since they are the heads of society and therefore, they deem the approach of the PDM as a total affront to African cultural norms.

Black feminism on the other hand, seeks to protest the dehumanization of women based on racial differences. Brahmitash (2008) posits that the western world believes that its cultures are superior, while other cultures are inferior. Here again, the concept of 'otherness' resurfaces. Colonialism was precisely about the subjugation of the African/Black. The colonial masters called their colonial enterprise in Africa, a civilizing mission. The Bible was the foundational document for the western colonial enterprise and the Bible decrees that the man shall be the head of the house, just as Christ is the head of the church (Ephesians 5:23).

The concept of black feminism is also akin to the arguments that we have made earlier about the stereotyping of people of color. When the SDM assert their blackness and their cultural identity as a symbol of pride, it is to reject the PDM and what they allege is the PDM's support for the superiority of white people. The SDM therefore, advocates for the articulation of a strictly African solution to what may seem like subjugation of women. And according to them, this African feminism should first of all, accept the fact thatwomen cannot achieve or bring about justice on their own. That is why they advocate cooking for men and massaging them so that men will feel happy enough to create the conditions that allow for the liberation of women.

In this section, we have invoked three important feminist theories to illuminate the arguments of both the PDM and SDM. Grounding their arguments in theoryhelps us to understand more clearly, the basis of their arguments. So, while the SDM is essentially, existentialist, the PDM can be referred to as radical feminists. In the next section, we present the major argument of the two groups regarding the cause of women's subjugation and what should be done about it.

\section{PDM Versus SDM: The Issue of Culture}

The major disagreement that the PDM and the SDM haverevolves around culture. The SDM postulates that in the fight for gender justice, the cultures and traditions of a people must be factored. The PDMis adamant about what its agenda is, which is that gender imbalance does not allow for men and women to work together "in unison to advance society" (www.pepperdemministries.com). They challenge the thesis put forth by Brahmitash (2008) and which the SDM echo, that the fight for gender justice ought to take into consideration, the cultural context of the people. PDM's mission is founded on refuting the argument on cultural context, "engaging with the issues which are mostly uncomfortable and unpopular in our socio-cultural space" (www.pepperdemministries.com). To them, the cultures of the Ghanaian people are the problem and not the solution. Western notions of gender justice may be unpopular in the Ghanaian socio-cultural space. Still, the PDM believes that if they will engender the change that is necessary to address the gender imbalance in Ghanaian society, then it is worthwhile to borrow western gender frames for the African context.

The PDM argues further that the argument about culture within an African context is misplaced. They aver that there is no homogeneous African culture, nor is there a homogeneous Ghanaian culture. There are disparate cultures and to lump all Ghanaian cultures together does not do justice to the fight for gender inclusiveness. It is precisely the point that Benedict (2006) as cited in Grewal and Kaplan (2006) makes that;

a basic problem in the construction of multi-culturalism is the assumption that all members of a specific cultural collectivity are equally committed to that culture. It tends to construct the members of minority collectivities as basically homogeneous, speaking with a unified cultural voice (p.219).

In this paper, we take the position thatwhile African cultures may be patriarchal and unfavorable to women like many societies across the globe, to use western gender frames as the basis for the fight for gender justice in the Ghanaian society, is misplaced. We also opine that SDM's approach to the struggle for gender justice will not engender the needed change. No oppressor ever handed over liberation to oppressed groups on a silver platter. So, for the SDM to want to "sugar" men to offer liberation to women belittles the struggle for gender justice.

We have argued in the section on theoretical framework, that existentialist theories of gender see the question of gender in binary forms. It is the binary conception of gender that gives life to the assertion of the male as 'self' and the female as the 'other.' However, modern conceptions of gender define or see gender beyond binary terms. Even in certain traditional African societies, gender is more than a strict bifurcation of the sexes into male and female. In some African cultures, 'men' can be 'women' and women can be 'men.' In Nankani society in Ghana, only males are considered heirs to their fathers. However, in certain instances, females are allowed to inherit their fathers and become heads of households if a father does not have a male heir at the time of his death. Amenga-Etego (2011) in discussing this phenomenon, says that when such a scenario occurs, a ritual of "calabash breaking" is performed to signal a total break of the female from the world of females. So that she is seen as male henceforth. 
In this ceremony of "calabash breaking, the woman in question holds a calabash on one end, and another male member of the family holds another end. Incantations are recited to the gods and at the end, they pull the calabash in opposite directions till the calabash breaks. Even so, the fact that a ceremony has to be performed before a female can play the role of a male, is still a tacit endorsement of male dominance.

In Ghana, there is always a pious outrage when any suggestion is made to the effect that, gender is not a strictly male-female dichotomy. Recently, there was a huge public outcry against a proposed Comprehensive Sexuality Education (CSE) policy in Ghana, when the government put out a draft that suggested that children in junior high schools may be taught to appreciate the fact that there are people who cannot be defined as strictly male or female. The refutations of Ministers of State, including the Minister for Education, was not enough to assuage the feelings of the society. It had to take the President to hold meetings with religious leaders, both Christian and Muslim, and to assure them that there was no agenda to recognize gay, lesbian, transgender and bisexual rights. The Ghanaian public said that the CSE was part of a grand scheme by the whites to impose their "perverted" gender views and practices on the Ghanaian people. The Spokesperson for the National Chief Imam of Ghana, Shaykh Aremeyaw Shaibu in a statement expressing the displeasure of the Muslim community about the policy wrote that "white people cannot compel us to accept anal sex. Anal sex is unnatural. If they want us to accept that anal sex is natural, they should also accept the practice of polygyny." Indeed, the office of the National Chief Imam described comprehensive sexuality education as "satanic" (www.ghanaweb.com).

For most Ghanaians therefore, gender is very much a binary between male and female. Anything in-between is an anathema and an abomination. By and large, the Ghanaian society is still very conservative and traditional. There may be isolated cultures like that of the Nankani which on some occasions recognize the female as 'male' after a ceremony is performed for that purpose. But the Nankani people remain a tiny minority who are confined to no more than a few villages in the remote corner of the Upper East Region of Ghana, towards the border with Burkina Faso. Their culture cannot be remotely conceived as anywhere near representative of dominant Ghanaian culture.

Because of the pervasive view in Ghanaian society that gender is indeed binary, the advocacy of the PDM group often receives a lot of backlash. The PDM group is made of women who, in the thinking of many Ghanains, are representative of all that is wrong with educating women to a higher level. In Ghana, there is the perception amongst some sections of the society that educating women to a higher level is injurious to the traditional order. It is believed that women, who gain higher education, question the customs and traditions of the society and imbibe foreign customs and traditions as promoted by the West. The least educated among the members of the PDM has at least a bachelor's degree. Some of them hold PhDs from American and British universities. Some of them are university professors, while others hold positions in government organizations.

The PDM and SDM debates continue to be interrogated in the public space in the context of this conservative culture of male dominance. Even within the social media space, the main opponents of the PDM group are educated Ghanaian women who have internalized the concept of male superiority and therefore see the advocacy of the PDM group as subversive of Ghanaian culture and traditions.

\section{Interrogating the Debate: A Middle Ground}

Having examined the main arguments of the PDM and SDM groups, we propose a middle ground model for engaging the issues of gender injustice. We contend that indeed the structures of the Ghanaian society, like many societies around the world, are biased against women. However, we posit that neither confrontation (PDM) nor pampering $(\mathrm{SDM})$ will address the issue of gender injustice in Ghanaian society. We propose what we call the middle ground. By middle ground, we mean a situation where women's groups engage positively and thoughtfully with the structures of society, through reasoned debate, lectures, publications, engagement and involvement in political parties and in the case of religion, engaging in what Shaikh (n.d) calls the "tafsir of praxis."Tafsir is the Arabic word for interpretation. But more specifically, the interpretation of the Qur'an. By "tafsir of praxis" Shaikh (n.d) means that people have to interpret the Qur'an according to their lived experiences. We therefore advocate for women to re-read the Qur'an from a woman's perspective (Wadud, 1999). Similarly, we advocate for engaging in the discourse of gender justice from the lived experiences and perspectives of women.

In advocating this position, we take a cue from the activities of a women's group in Malaysia called Sisters in Islam (SIS). SIS has been able to navigate the complex patriarchal structures of the Malaysian society to claw back some space for Malaysian women. This is in spite of the fact thatthe Malaysian state has "brought into the power structure, various politicized Islamist groups, as well as tribal and conservative leaders who do not believe in equality or reformist Islam" (Othman (2006, p.2). This the SIS achieved this through advocacy and research, memoranda to government protesting the treatment of women and challenging national laws that are inimical to women. More so, SIS published several articles on issues affecting women in the national dailies, organized public lectures, seminars and workshops. Also, they created networks of like-minded groups and established a resource center "containing about 2000 books, journals and articles on Islam, with particular focus on writings on progressive Islam, women's rights, human rights and on Islam and politics" (Othman, 2006, p.12). 
In a conservative society like Malaysia, SIS members are often attacked for their views and labeled as western apologists, who are a threat to the very survival of Malaysian society. In spite of the dangers that they face, the work of SIS remains a bulwark against the vulgar bastardization of the rights of women in the name of Islam.

We suggest that the PDM should adopt the SIS's model of positive engagement that addresses the real issues confronting women. The vitriolic hardline attacks on patriarchal structures are construed by the Ghanaian public to be an attack on men and almost automatically alienates the men and even some women as it did with the women of the SDM. We agree with Kwapong (2009) when she states that "indicators for gender equality cannot be achieved without the full involvement of males and boys" (p.154). Therefore, rather than antagonize men, men should be engaged positively.

Rinaldo (2010) takes up a similar subject in Indonesia. She highlights the activities of Rahima, a women's group and the Prosperous Justice Party (PKS), which was founded in 1998 and which proclaims Islam as its ideological underpinning. Both the women of Rahima and the women of the PKS are very visible in the public place. Indonesia is the most populous Muslim nation on earth and it is quite conservative. But through positive engagement, women have been able, like the SIS of Malaysia, to establish a presence and advocate for the rights of women. On the ticket of the PKS, many women have been able to win parliamentary seats.

From the examples of SIS, Rahima and the women of PKS, we postulate that the strategies of both the PDM and the SDM are misplaced. We find the approach of the PDM too confrontational and alienating, while at the same time we find the strategy of the SDM too weak for effect. No group of oppressed people have ever been granted their freedom from liberation through the benevolence of the oppressor. So, the strategy of the SDM to "sugar" men will not yield the right results. A middle-ground strategy of positive engagement with the structures of society is what would yield results. The SIS in Malaysia and Rahima in Indonesia have shown that the middle ground strategy works, even if the women of Indonesia and Malaysia are still far from achieving total gender justice.

\section{Conclusion}

Ever since the Beijing Declaration of 1995, the women of Ghana have been active in the fight for gender justice. The Ghanaian state itself has been building structures to facilitate the development of women. It first established the National Council on Women and Development (NCWD). In 2001, the government elevated the department to ministerial status at the cabinet level and called it the Ministry of Women and Children's Affairs. Subsequently, the ministry has been refocused and renamed the Ministry of Gender, Children and Social Protection. Within the private sphere, groups like the Network for Women's Rights (NETRIGHT) and ABANTU for Development spearheaded the effort towards the attainment of gender justice in Ghana. They even produced a Women's Manifesto to serve as a blueprint for the fight for gender justice.

With the advent of new media, a new crop of young upwardly mobile women has emerged as the new champions of the fight for gender justice. In 2017, these young women formed two distinct groups with totally different views about how to achieve gender justice. These groups are the PDM and the SDM. The PDM positioned itself as a radical feminist group with a strategy to confront head-on, the patriarchal structures that inhibit the development of women. The SDM on the other hand, advocated a "sugared" approach to achieving gender justice. Our contention is that both strategies are misplaced. Rather we advocate a strong but measured approach to tackling the issue of gender injustice. The examples of SIS in Malaysia and Rahima in Indonesia are a good model that both the PDM and the SDM could adopt for Ghana.

\section{References}

Abdul-Hamid, M. (2017). Islam and Gender in Dagbon. Unpublished Ph.D. thesis, submitted to the Department of Religion and Human Values, University of Cape Coast, Ghana

Alhayek, K. (2014). "Double marginalization: the invincibility of Syrian refugee women's perspectives in mainstream online activism and global media" in Feminist Media Studies, Vol 14, Issue 4

Amenga-Etego, R. (2011). Mending the broken pieces: indigenous and sustainable rural development in Northern Ghana. New Jersey: World Press

Benedict, A. (2006). "Imagined communities: reflections on the origin and spread of nationalism" in (ed), Grewal and Kaplan, An introduction to women's studies- gender in a transnational world (second edition). New York: McGraw Hill

Brahmitash, R. (2008). "Saving Iranian women: orientalist feminism and the axis of evil" in (ed), Sutton et al, Security disarmed: critical perspectives on gender, race and militarization. New Jersey: Rutgers University Press.

Hall, S. (1997). Representation: cultural representations and signifying practices. London: Sage Publications.

Kwapong, O.A.T.F. (2009). Male support for gender equality. Accra: Ghana Universities Press.

Pratt, G \& Rosner, V. (2012). "Introduction: the global and the intimate" in (ed), Pratt \& Rosner, The global and the intimate: feminism in our time. New York: Columbia University Press. 
Rinaldo, R. (2010). "The Islamic revival and women's political subjectivity in Indonesia” in Women's studies international forum, 33

Said, E.W. (1978). Orientalism. London: Penguin Books

Ong, A. (1999). Flexible citizenship: the cultural logistics of transnationality. Durham, NC: Duke University Press.

Othman, N. (2006). "Muslim women and the challenge of Islamic fundamentalism/extremism: An overview of the Southeast Asian Muslim women's struggle for human rights and gender equality" in Women's Studies International Forum, 29.

Shaikh, S. (n.d). "A tafsir of praxis: gender, marital violence and resistance in a South African community" in Violence against women in contemporary world religions (ed), Daniel Maguire \& Shaikh Sa'diyya. Cleveland: Pilgrims Press.

Wadud, A. (1999). Qur'an and woman: rereading the sacred text from a woman's perspective. Oxford: Oxford University Press.

Andoh, K. I. (2018). International Women's Day and critical look at The Dems (Pepper and Sugar).Retrieved from https://www.myjoyonline.com/opinion/2018/march-9th/international-womens-day-and-critical-look-at-thedems-pepper-and-sugar.php

Comprehensive Sexuality Education: "I will not destroy Ghana's cultural values". Akufo- Addo reiterates. Retrieved from https://www.myjoyonline.com/news/2019/October-14th/akufo-addo-reiterates-stand-onsexuality-education.php

Osman, K. (2019). Drop "Satanic" sex education programme. Retrieved from https://www.ghanaweb.com/GhanaHomePage/NewsArchive/Drop-satanic-sex-education-programmeChief-Imam-785298 